\title{
Porto de Trás: etnicidade, turismo e patrimonialização
}

\section{Patrícia de Araújo Brandão Couto ${ }^{i}$}

Universidade Federal Fluminense

\begin{abstract}
Resumo: Este artigo tem por objetivo discutir o recente processo de patrimonialização cultural do bairro do Porto de Trás, da cidade de Itacaré, situada no litoral sul do estado da Bahia; uma comunidade étnica de afro-descendentes, tradicionalmente vinculada à pesca artesanal. Historicamente, os moradores deste bairro, agrupados pelo pertencimento familiar, foram segregados no espaço urbano por implicações raciais e sócio-econômicas. Com a introdução do turismo nos anos de 1990, o bairro, que se preservou dos novos processos de ocupação, manteve suas práticas culturais e passou a ser reconhecido como um reduto de "autenticidade" da cultura local. Pretendemos abordar os processos de interação entre as esferas patrimoniais atuantes neste espaço turistificado, enfocando particularmente a constituição da etnicidade dos moradores desta área.
\end{abstract}

Palavras-Chave: Turismo; Etnicidade; Patrimônio Cultural; Itacaré (BA); Populações Afro-brasileiras

Title: Porto de Trás: ethnicity, tourism and the recognition of heritage

Abstract: The article describes the process by which cultural heritage of Porto de Trás, a neigborhood in Itacaré on the southern coast of Bahia, Brazil, has gained recognition. Porto de Trás is an ethnic community of African Brazilians with a tradition of artisanal fishing. Historically, its residents, organized in family groupings, have been segregated for their race and socioeconomic status. Even with the arrival of the tourist industry in the 1990s and concomitant urban developments, it maintained its traditional cultural practices, gaining recognition as an enclave of "authenticity" referred to local culture. Interactions between the different spheres of heritage operating in this space are discussed especially the construction of ethnicity by local residents

Keywords: Tourism; Ethnicity; Cultural Heritage; Itacaré (Bahia/ BR); African Brazilians. 


\section{Introdução}

Este $\operatorname{artigo}^{1}$ tem por objetivo discutir o recente processo de patrimonialização cultural do bairro do Porto de Trás, uma "comunidade étnica de afro-descendentes" (Barth, 2000) tradicionalmente vinculada à pesca artesanal e às atividades portuárias da cidade de Itacaré, situada no litoral sul do estado da Bahia. Enquanto a cidade foi um porto de escoamento da produção de cacau da região - entre os anos de 1900 e 1960 - os moradores deste bairro, agrupados pelo pertencimento familiar, foram segregados no espaço urbano por implicações raciais e sócio-econômicas. Com a introdução da economia turística nos anos 1990 e o subseqüente processo de reconfiguração urbana, o bairro, que se preservou dos novos processos de ocupação, manteve suas práticas culturais e incorporou os novos sentidos da afro-baianidade, passou a ser reconhecido como um reduto de "autenticidade" da cultura local.

Compreendendo a multiplicidade de sentidos que o patrimônio como categoria de pensamento evoca, entendemos como "patrimonialização" os diferentes processos de resignificação e reapropriação desta categoria pelos distintos grupos de interesse que o atualizam em termos normativos e pragmáticos. Neste sentido, pretendemos abordar os processos de interação entre as esferas patrimoniais atuantes neste espaço turistificado, privilegiando o enfoque de reapropriação do ponto de vista nativo. Interessa-nos em particular, analisar os alicerces culturais que possibilitaram a constituição da etnicidade de seus moradores, essencial para o processo de inversão simbólica na condição urbana do Porto de Trás, um bairro historicamente estigmatizado, que se distinguiu por uma identidade cultivada e na atualidade patrimonializada em diferentes sentidos.

A seguir, apresento os parâmetros conceituais com os quais pretendo dialogar na presente situação etnográfica ${ }^{2}$, estabelecendo neste caso, as interfaces entre patrimônio e turismo, para ao longo da analise etnográfica demonstrar o processo de constituição da "etnicidade" (Barth, 1994) dos moradores do Porto de Trás, ao vivenciarem o fenômeno turístico e refletirem sobre as atribuições internas e externas à identificação do grupo.

\section{O patrimônio em sua multiplicidade de sentidos}

Ao discutir a noção de patrimônio entendido como portador de memória coletiva, Le Goff (1998) identifica três fases históricas para a configuração desta noção. Num primeiro período, está associado ao processo de formação dos Estados Nações, quando seu sentido foi ancorado pelo Estado na identificação de símbolos de um passado nacional comum. Seu uso crescente entre as duas grandes guerras mundiais, inaugura uma segunda fase quando passa a ser apropriado por instituições e organizações internacionais. A partir dos anos de 1960, a noção de patrimônio expande-se de sua condição histórica para sua condição social; do patrimônio herdado ao reivindicado; de sua percepção visível e material a uma percepção invisível e imaterial.

A noção de patrimônio intangível se vincula a moderna concepção antropológica de cultura, uma vez que seu sentido desmaterializado e simbólico o permite trafegar no plano do intangível. Na atualidade, as diferentes abordagens que convergem para o reconhecimento de um patrimônio e os significados que lhes são atribuídos não se excluem, pelo contrário, são complementares, posto ser necessário haver "ressonância" para a identificação de um objeto como patrimônio (Gonçalves, 2004). Neste sentido, patrimônio e memória coletiva, formam um léxico de expressões cuja característica principal é a multiplicidade de sentidos que lhes são atribuídos, tanto pelo senso comum, quanto por agentes estatais especializados em coletar fragmentos culturais.

Portanto, como lugar da identidade de um passado resguardado ou evocação necessária do presente e do futuro, como formas fixas ou intangíveis, porém portadoras de tempo e de vivências, a expressão ao longo do tempo acumulou uma 
série de noções que se configuraram num vasto campo semântico. Justo por isto, Gonçalves (2003) nos sugere posicionar o patrimônio como "categoria de pensamento", presente em toda e qualquer sociedade humana. Em outras palavras, é necessário identificar e comparar os diversos contornos semânticos da categoria patrimônio para compreendê-la no tempo e no espaço, estabelecendo as distinções entre o que é normativo e o que é pragmático sobre o patrimônio.

Isto significa dizer que em qualquer situação que a questão patrimonial se imponha, não devemos pensá-la como um construto único, de amarras bem definidas e um sentido comum para o seu emprego. Seus sentidos e significados estão diretamente associados aos atores, grupos, agentes e agências que fazem uso do conteúdo desta categoria, o que implica em afirmar que não necessariamente um grupo ou segmento social que possui um patrimônio cultural faça uso desta expressão de forma direta. Muitas vezes, principalmente entre os grupos étnicos de origem ágrafa, como é o caso dos moradores do bairro do Porto de Trás, a compreensão do conteúdo patrimonial pode estar condensada no plano simbólico, onde se produzem os sentidos culturais.

Em termos etnográficos, tanto o "patrimônio" quanto o "fenômeno turístico" podem ser qualificados como "fatos sociais totais" (Mauss, 1974) porque se caracterizam como elementos mediadores que atravessam diversos planos simbolicamente construídos no domínio social (Couto, 2007b). Na situação em questão é o turismo, como "rizoma" (Barretto, 2003) ${ }^{3}$, que em sua imprevisibilidade permite o engendramento de uma multiplicidade de sentidos patrimoniais e produz uma nova consciência étnica nos moradores do porto.

\section{Um pouco da história do município}

De acordo com os habitantes do município, a história de Itacaré se divide em duas fases: antes e depois da construção da estrada (1996-1998). Contam os mora- dores que a cidade teve sua origem numa aldeia indígena Guerém catequizada pelos jesuítas que aí vieram se instalar no início do século XVIII e introduzir o plantio da cana-de-açúcar.

Os catequizadores construíram uma

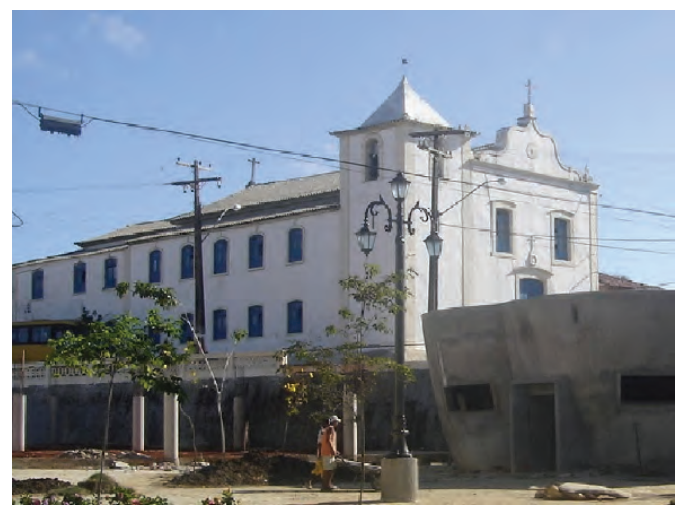

Igreja de São Miguel e Monumento ao Cacau (Foto: Patricia A. B. Couto)

capela em homenagem a São Miguel e batizaram a nova povoação de São Miguel da Barra do Rio de Contas no ano de 1718. Por sua extensa possibilidade de navegação, ainda no século XVIII, o Rio de Contas transformou-se no eixo de ligação entre o interior da Chapada Diamantina e o litoral, no qual São Miguel da Barra do Rio de Contas servia como apoio náutico devido às condições facilitadoras de sua foz. Assim, a pequena vila, devido a sua localização no encontro das águas ribeirinhas junto ao mar, acabou por se constituir num ponto estratégico para embarque e desembarque de produtos da época e para o tráfico de escravos que serviam às fazendas locais.

A cana de açúcar não vingou como produto regional. Foi somente em meados do século XIX que a região do litoral sul do estado saiu de sua condição de fornecedora de produtos de subsistência para ganhar relevância econômica e se tornar a principal região produtora de cacau do estado (Falcon, 1995) ${ }^{4}$. A partir deste período, o porto de Barra do Rio de Contas ganhou um novo sentido. Como único vínculo de transporte náutico entre a região e a capital de São Salvador, passou a drenar toda a produção cacaueira do sul do esta- 
do da Bahia.

Até então, habitado essencialmente por pescadores e ribeirinhos, muitos deles de origem indígena ou filhos e netos de escravos, oriundos, tanto dos quilombos e mocambos regionais (Spix e Martius, 1981; Reis, 2005) $)^{5}$ quanto das fazendas locais, o pequeno povoado passou a atrair e agregar novos interesses de segmentos sociais mais abastados. A intensidade da vida comercial do Rio de Contas decorrente da riqueza obtida com o cacau fez com que o povoado de São Miguel ganhasse ares de vila. Durante o terceiro ciclo do cacau (1895/1930), luxuosas casas de veraneio foram construídas pelos fazendeiros do interior e comerciantes, que passaram a residir na área do porto. Assim, em torno da igreja de São Miguel, no alto de uma pequena colina junto ao mar, desenvolveu-se o centro da vila.

A região portuária ganhou construções portentosas que estampavam a riqueza de seus proprietários. A abastança começa a se esvair no final da década de 20, quando o porto de Barra do Rio de Contas perde parte de sua importância estratégica para o escoamento da produção cacaueira. Esta perda se deveu essencialmente a dois fatores: a construção do porto de Ilhéus entre os anos de 1920 e 1926 e a extensão ferroviária que conectou os povoados desta área ao novo porto, mais central para a região sul. A partir de 1931, o município e sua sede passam a se chamar Itacaré. Embora tenha perdido sua relevância portuária regional, seu porto continuou a escoar a produção municipal e a embarcar os passageiros que rumavam para Salvador até o final da década de 1960, quando foi desativado devido ao assoreamento crescente do Rio de Contas.

O fechamento do Porto de Itacaré encerrou seus habitantes num relativo isolamento uma vez que a população, antes acostumada à circulação costeira permitida pela navegação passou a enfrentar sérias dificuldades de circulação devido a seus frágeis caminhos terrestres. Esta situação se agravou ainda mais com a crise econômica do cacau nos anos de 1980, por decorrência da queda do produto no mercado internacional e a subseqüente incidência do fungo chamado "vassoura de bruxa", uma praga que varreu as plantações de cacau do sul do estado da Bahia. A partir de então o município entrou em franca decadência por não dispor de outros produtos que mobilizassem recursos para a região.

A "crise do cacau" não afetou somente o município, mas todo o sul do estado da Bahia. Os baixos preços ditados pelo mercado e a ausência de um fruto saudável, provocaram o endividamento dos fazendeiros, o desemprego de grande parte dos trabalhadores rurais e a estagnação da economia municipal.

Dentre as estratégias governamentais

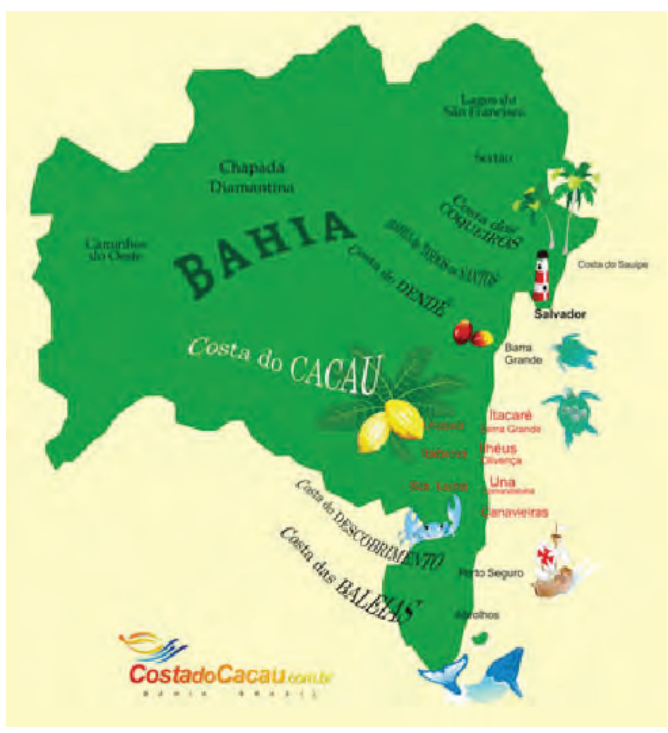

Fonte: http://www.costadocacau.com.br/pt/ costadocacau.php

para reordenar a economia do estado, foi criado no ano de 1991, o PRODETUR/ BAHIA - Plano de Desenvolvimento do Turismo da Bahia - com a finalidade de reposicionar a indústria turística estadual no ranking nacional.

Este planejamento elaborou uma série de metas e redesenhou a geografia turística do estado dividindo-o em seis áreas: Costa dos Coqueiros, Costa do Dendê, Costa do Descobrimento, Costa das Baleias, Costa do Cacau e Chapada Diamantina. Como resultante do planejamento governamental para a expansão 
e implantação de novas áreas turísticas, o município de Itacaré, situado na então denominada Costa do Cacau e possuidor de um dos últimos redutos da mata-atlântica, foi beneficiado com a construção da Estrada Parque Ilhéus-Itacaré, entre os anos de 1996-1998.

Observa-se, portanto, a atribuição de valores patrimoniais por parte do Estado com relação à demarcação de seus possíveis territórios turísticos. Em outras palavras, o estado nomeou os futuros territórios turísticos de acordo com suas características naturais, culturais e históricas, com o intuito de viabilizar economicamente o projeto governamental perante as agências de fomento internacional a exemplo do Banco Interamericano de Desenvolvimento (BID) que teve intensa participação na concretização do projeto turístico estatal (PRODETUR/ BAHIA) e posteriormente na efetivação do PRODETUR NE I (Couto, 2007) ${ }^{6}$.

No caso do município de Itacaré, o selo patrimonial atribuído pelo Estado está associado ao imaginário coletivo posto que no plano simbólico, vincula o território municipal às representações da "cultura do cacau e seus coronéis", extensamente divulgada nas publicações internacionais da literatura produzida por Jorge Amado, evocando o patrimônio cultural da região. Mas a sustentabilidade econômica do projeto foi viabilizada por seu patrimônio natural, através da criação de uma Área de Proteção Ambiental na mata atlântica do município. Portanto, o selo patrimonial recorre aos recursos naturais e culturais da região.

Implementada com finalidades a priori econômicas, a estrada rapidamente atingiu seu objetivo, pois se antes Itacaré era freqüentada somente por veranistas baianos, viajantes alternativos e surfistas em busca de paraísos naturais e ondas perfeitas que enfrentavam as difíceis condições de acesso terrestre para usufruir das belas paisagens do município, a partir de então, esta localidade tornou-se acessível nacional e internacionalmente. A facilidade de acesso, além de possibilitar a presença de fluxos populacionais sazonais, acarretou uma onda migratória em direção à região, tanto por parte das populações circunvizinhas em busca de novas oportunidades econômicas, quanto por parte de pequenos empresários e grandes especuladores imobiliários internacionais e nacionais, vindos da região sudeste. Tais transformações decorrentes do processo de absorção do fenômeno turístico têm desencadeado a re-configuração social, econômica, territorial e simbólica das áreas urbanas e rurais do município (Couto, 2007a).

De fato, a estrada trouxe os turistas e o turismo reaqueceu a economia municipal com a presença de novos investidores que instalaram pousadas, hotéis, agências e operadoras ecoturísticas na localidade, mas as novas oportunidades de trabalho também atraíram outros "estrangeiros" (Simmel, 1983) dispostos a encontrar um lugar no mercado de trabalho insurgente. As novas "co-presenças"(Urry, 2005), conseqüentes à facilidade de acesso e mobilidade, acabaram por gerar uma espécie de antagonismo latente entre aqueles que são considerados como "de dentro" e "de fora" do município (Couto, 2006), ou seja, antigos e novos moradores ou "estabelecidos e outsiders” (Elias e Scotson, 2000), uma vez que o "princípio da antiguidade" vem acirrar as reivindicações pelo "direito ao lugar" e ao mercado de trabalho insurgente.

As disputas nas relações de poder, explicitadas nos pares de oposição; superioridade e inferioridade moral e social; auto-percepção e reconhecimento; exclusão e pertencimento; passaram a atravessar de forma objetiva as condições existenciais de seus habitantes, que lutam para encontrar uma posição na nova hierarquia sócio-econômica local posto que o fluxo populacional que afluiu para o município reconfigurou valores, hábitos, costumes e redesenhou as territorialidades urbanas e rurais do lugar (Couto,2006). Mas o fenômeno turístico, como um "rizoma", segue os caminhos do imponderável e se por um lado reifica a acertiva de seu impacto avassalador e mutante para as localidades onde aporta, por outro, pode reservar gratas surpresas para os que dele partici- 
pam ou o observam.

\section{A cidade como lugar: para entender a paisagem}

Para um espaço ser reconhecido como lugar, é preciso que tenha sido contornado e preenchido de sentidos, histórias, memórias e representações, produzidas tanto pela humanidade que o habita, quanto pelos demais coletivos com o qual interage, uma vez que as identidades sociais são processos resultantes de interações coletivas.

Ezra Park (1976) em seus estudos de Ecologia Humana constata que os ho-

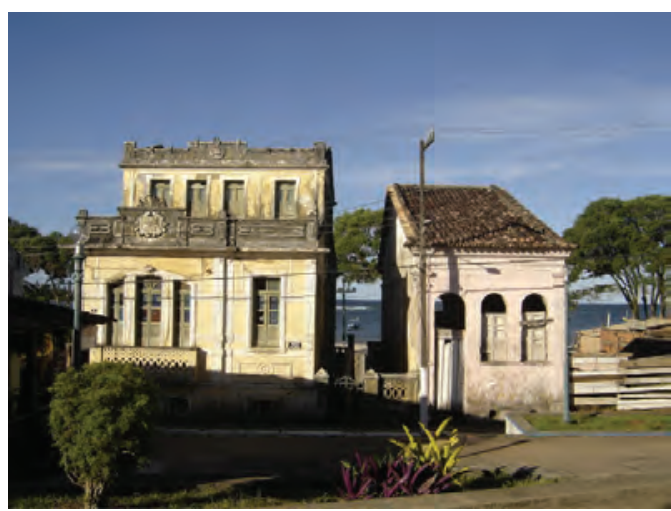

Remanescente da época de auge do cacau no centro da cidade (Foto: Patricia A. B. Couto)

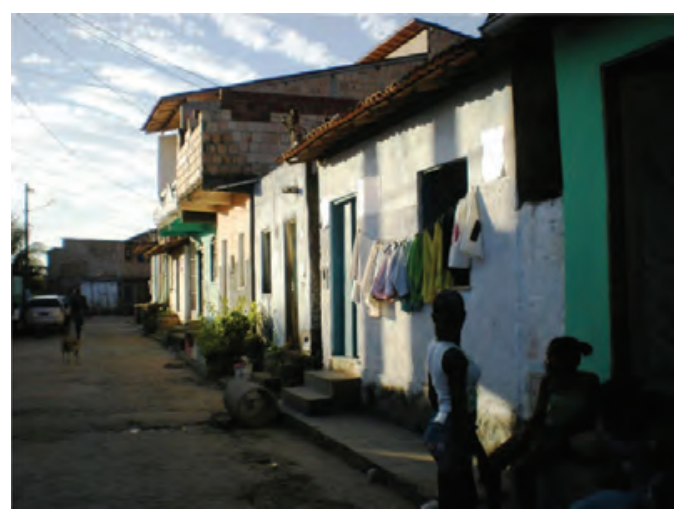

Uma lateral da rua principal de Porto de Trás (Foto: Patricia A. B. Couto)

mens se organizam segundo dois princípios ecológicos que operam para estabelecer uma ordem comunal. Estes princípios são denominados como de "dominância e sucessão": o primeiro refere-se às chama- das áreas naturais, a partir das quais os homens se organizam; o segundo obedece à lógica das seqüências ordenadas de mudança e que no caso dos aglomerados urbanos refere-se ao processo de expansão nas diferentes direções. Dos doze bairros atuais da cidade de Itacaré somente quatro fazem parte de sua formação original,

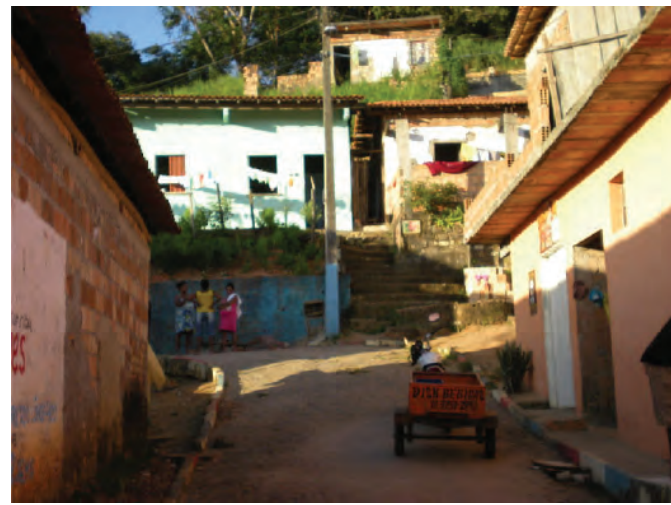

Segunda rua; fruto do crescimento populacional do porto (Foto: Patricia A. B. Couto)

quero dizer, são anteriores a construção da estrada, finalizada no ano de 1998: o Centro, o Porto de Trás, o Marimbondo e o Angelim.

O Centro, que se estende pela Orla ou Praia da Coroa, no passado fora reconhecido por seus casarões de grande porte como o bairro da elite branca do lugar, formada por comerciantes e grandes proprietários da cultura cacaueira e em torno do qual se estabeleceu o centro administrativo e comercial da cidade. O declínio da economia cacaueira teve por conseqüência a decadência de seus casarões e a mudança no perfil dos habitantes que ali permaneceram como a gente branca e remediada do lugar. O bairro manteve-se como centro administrativo e aos poucos foi se tornando uma área de cobiça para o desenvolvimento das atividades turísticas que na década de 1990 começaram a despontar e que ao longo dos últimos anos foram responsáveis pela revitalização da área. Como ocupação "sucessiva” na área sul da cidade existia somente o bairro do Angelim, um bairro de pescadores contíguo ao Centro e que com o processo de turistificação foi parcialmente integrado às 
atividades comerciais de novos moradores.

Posicionados a noroeste do centro, portanto situados na área ribeirinha, permaneceram incrustrados e quase invisíveis atrás do morro do cemitério, os bairros do Porto de Trás e do Marimbondo. Situado às margens do Rio de Contas, o Porto de Trás, teve sua origem no agrupamento das famílias Cruz, Souza, Silva, Santos e Rocha, cuja estreita relação de parentesco é explicada pelos moradores como resultante da proveniência do grupo, que teria se originado no antigo quilombo do Oitizeiro (Reis, 2005), em tempos idos, estabelecido rio acima.

Apesar dos sobrenomes citados, todos se consideram como pertencentes a uma única família e isto é o que se verifica, quando se passeia pelo pequeno bairro, onde a entrada de carros é socialmente recriminada já que as crianças brincam na rua até o anoitecer, sob os olhos e cuidados da extensa parentela de tios, avós e primos que os cerca. Cerca de 400 pessoas vivem na área do Porto de Trás. Estas famílias, que vivem da atividade pesqueira e que anteriormente também trabalharam na estiva do porto, ainda hoje são conhecidas pela forma reservada como mantiveram a privacidade dos moradores estabelecidos na longa e estreita rua que desemboca no rio, e que atualmente conta com um segundo quarteirão de casas construídas num sentido paralelo à mesma.

Dando continuidade à ocupação predominante nas margens do rio, na área interior ao Porto, situa-se o Marimbondo. Segundo seus moradores - também em sua grande maioria negros - esta área teve por origem um aglomerado de casas de taipa, construídas pelos ribeirinhos de mesma proveniência, que desceram o rio para comercializar os produtos de suas roças e trabalhar nas docas do porto de escoamento do cacau. Apesar de propiciar uma leitura exterior de continuidade étnica e identitária, devido à sucessão espacial que une os dois bairros ${ }^{7}$ e dos vínculos de parentesco e práticas culturais comuns, os dois lugares não se reconhecem por uma identidade única, em decorrência da alegada diferença de procedência familiar, muito embora admitam a existência de relações de parentesco.

O que se percebe é que existe uma relação de complementaridade entre as duas áreas, mas que estas cultivam certa rivalidade com relação à legitimidade e ao reconhecimento dos legados culturais que lhes são atribuídos. São estes legados que

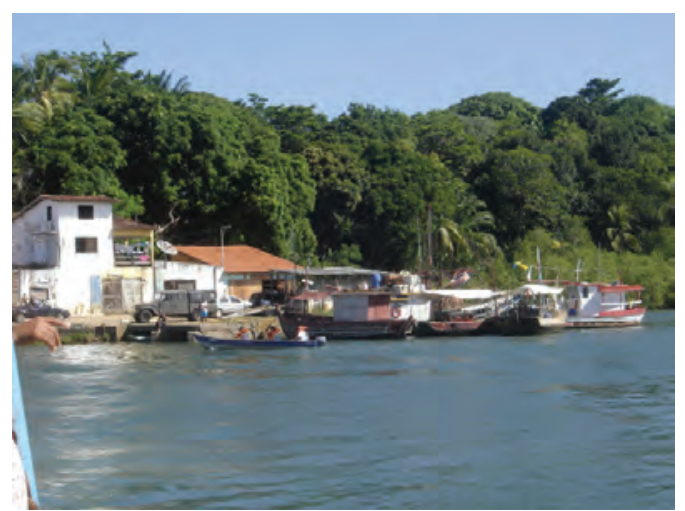

Porto de Trás da perspectiva do Rio das Contas (Foto: Patricia A. B. Couto)

conferem aos dois bairros uma posição diferenciada perante as demais áreas de ocupação. Mas é fato que após a construção da estrada, somente o Porto de Trás manteve sua configuração anterior, preservando-se espacialmente da heterogeneidade sócio-cultural desencadeada pelo fenômeno turístico.

Já o Marimbondo, tornou-se uma área de passagem para as novas áreas de ocupação: a "Baixa da Gia", uma estreita faixa de mangue, ocupada pelos ribeirinhos que desceram da área rural à procura de trabalho nas atividades turísticas e a "Passagem", uma área de desdobramento da população nativa, recentemente ocupada por algumas pousadas construídas na beira do Rio de Contas e por moradores provenientes de outras localidades. Portanto o Marimbondo não foi preservado do processo de hibridização da nova configuração urbana e suas singularidades fronteiriças diluíram-se na paisagem.

Além dos dois novos bairros na área noroeste da cidade surgiram na área sul e oeste da faixa litorânea: a Pituba, um 
bairro ícone da integração local atual, reconhecido pela complexa mistura de seus habitantes - pescadores, surfistas e alternativos; Conchas do Mar I e II, que em toda sua extensão litorânea concentra as principais pousadas de bom padrão de Itacaré; São Miguel ou Alagados, um pequeno trecho de habitações precárias entre a Pituba e os loteamentos da Concha; Alto da Ribeirinha, que vem se constituindo como um bairro de moradia para padrões médio e alto em oposição ao seu vizinho

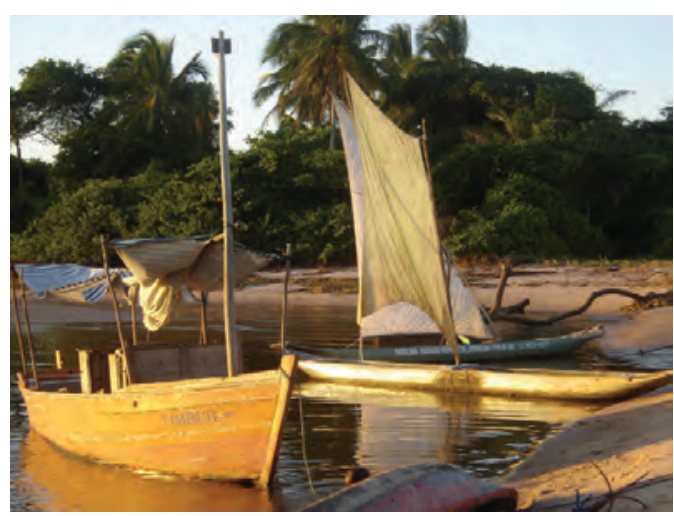

Canoas de pesca no Rio das Contas (Foto: Patricia A. B. Couto)

Bairro da Linha, também conhecido como Santo Antonio e reconhecido localmente como uma área de expansão desordenada da cidade, que acolheu as populações rurais e circunvizinhas atraídas pelas novas oportunidades de trabalho.

\section{Singularidades do Porto de Trás}

Como o processo de hibridização turística tende por vezes a descaracterizar ou tornar difusos os traços culturais originais das localidades onde este fenômeno aporta, a manutenção das singularidades culturais e identitárias do bairro do Porto de Trás, fez com que esta área se tornasse um símbolo de resistência cultural dos novos tempos citadinos. Ironicamente, o que se percebe neste caso em particular, é uma inversão dos valores, uma vez que os bairros do Porto de Trás e do Marimbondo passaram a ser reconhecidos no imaginário urbano como os guardiões da "cultura autêntica" da cidade de Itacaré.
Digo ironicamente, porque no passado, durante o auge da cultura cacaueira, os dois núcleos contíguos de ocupação, tinham suas representações como lugares, remetidos ao espaço de moradia dos negros, ex-escravos, servidores dos senhores do cacau, confinados no que os próprios moradores do Porto e do Marimbondo denominam como a "antiga senzala da cidade". A geografia deste confinamento

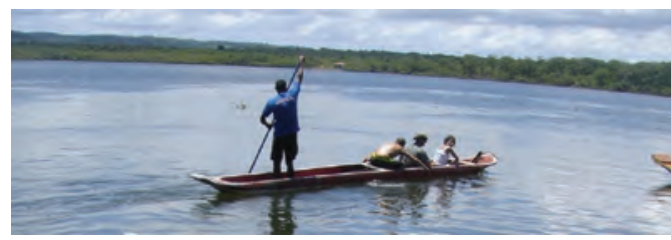

Moradores do porto na saída para a pesca e para passeios turísticos (Foto: Patricia A. B. Couto)

se revela na própria posição que ocuparam dentro do espaço urbano. Enquanto os brancos ricos ou remediados do lugar, se fixaram na região de "dominância" e construíram seus casarões na colina ou beira mar, os pretos e pobres elevaram suas casas de taipa numa área sucessiva beira rio, num espaço de sombra, invisível à vigilância e abastança dos primeiros.

Esta segregação racial, social e econômica, explicitada na própria configuração do espaço urbano em suas áreas de confinamento e interação social, permitiu a constituição da etnicidade dos negros do Porto de Trás e do Marimbondo. Entendo o conceito de etnicidade no sentido que lhe confere Frederick Barth (2000), ou seja, uma identidade étnica que se concebe como dinâmica e interativa e que se mantém de forma duradoura pela eficácia de sua atualização nos processos de distinção entre o nós e os outros. Portanto, não se trata da preservação de práticas culturais por uma situação de isolamento, mas sim, de uma identidade cultivada e propiciada pela construção de referenciais étnicos amparados nas relações de pertencimento, exclusão, segregação e interação entre os moradores do bairro e os demais habitantes da cidade.

A coesão interna se justifica em princípio por uma argumentação que se articula em torno do porto como um espaço 
comum a famílias negras que se uniram por alianças matrimoniais até constituírem uma coletividade. A história real ou suposta do lugar remete seus fundadores a remanescentes do quilombo do Oitizei$\mathrm{ro}^{8}$, a escravos foragidos das fazendas e dos navios negreiros que por ali passavam. Reclusos nesta área de ocupação cultuaram seus ancestrais e perpetuaram a solidariedade étnica através de práticas culturais que sobrevivem nas "festas do Porto", tais como o samba de roda, a folia de reis, o bicho caçador, a capoeira dos estivadores e as festas de São João. Portanto, um "banco de símbolos" (Sansone, 2000) amalgamado por uma identidade cultivada. Observa-se deste modo que os operadores simbólicos desta etnicidade se constituem a partir de um território comum entre partícipes de uma história real ou suposta que os uniu por laços consangüíneos e traços culturais perpetuados em suas práticas sociais independente

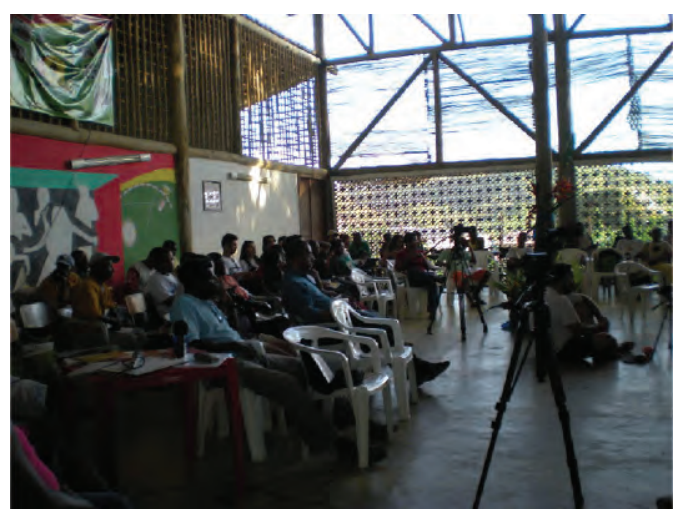

Atividade na Associação de Moradores do Porto de Trás (Foto: Patricia A. B. Couto)

dos infortúnios da exclusão.

Um fator essencial para a renovação e cultivo desta identidade foi a "chegada da estrada". Isto se explica pelo fato de que entre as décadas de 1960 e 1990, o assoreamento do Rio de Contas e as dificuldades de acesso terrestre, mantiveram a cidade de Itacaré num relativo isolamento, consequentemente, a população do Porto de Trás e do Marimbondo permaneceu vinculada à atividade tradicional pesqueira, mantendo-se contida pelos limites da divisão social do trabalho e dos estigmas decorrentes. A construção da estrada permitiu não somente a chegada de novos moradores e oportunidades de trabalho, mas facilitou sobremaneira a circulação dos antigos moradores que até então sofriam com a dificuldade de deslocamento. Neste sentido, a população jovem do Porto teve uma oportunidade diferenciada ao entrar em contato com outras realidades e localidades.

Ainda na década de 1990, muitos moradores jovens do Porto foram para Salvador e a livre circulação permitiu-lhes uma expansão da consciência cultural e política. $\mathrm{O}$ acesso às questões emergentes no movimento negro, o discurso pela valorização da cultura afro-baiana, o cultivo da auto-estima e a entrada no fluxo da cultura do Atlântico Negro, através de interações com o movimento rastafari e com o "banco de símbolos" das africanidades afro-baianas contemporâneas, redimensionaram a consciência étnica destes jovens. Ao retornarem ao Porto de Trás, levaram consigo novos ingredientes para a atualização da etnicidade de seus moradores. Digo atualização porque não negaram as práticas culturais de seus pais e avós, pelo contrário, reforçaram a importância de seus legados culturais, portanto patrimoniais, ao mesmo tempo em que incorporaram o estilo da negritude baiana atual e passaram a investir na manutenção da coesão grupal.

Ao refletir sobre as "temáticas permanentes e emergentes na etnicidade", Barth(1994), atualiza suas proposições face às questões emergentes e estabelece três níveis ou planos interpenetráveis para compreendermos as forças que interagem na formação de uma identidade étnica. No nível micro, modela-se os processos que produzem a experiência e formação das identidades; no nível médio, identificado como o campo da liderança e da retórica, criam-se os processos que mobilizam os grupos para diversos propósitos; no nível macro, referendado no Estado, está as criações de burocracias que distribuem direitos e proibições de acordo com critérios formais.

No caso específico do Porto de Trás, o 
"nível micro" se explicita através da cultura compartilhada e cultivada pelo grupo, que mesmo passando por uma longa trajetória de estigma e segregação racial, não abre mão de seus valores, suas práticas e de seu patrimônio cultural perpetuando-o através de gerações. $\mathrm{O}$ nível médio surge justamente quando os jovens do porto, ao saírem da localidade encontram a ressonância de suas praticas culturais de origem no "banco de símbolos" das africanidades afro-baianas contemporâneas, tomam consciência de seu patrimônio cultural e retornam com novos ideais, valorizando a unidade e a coesão grupal, fundando inclusive, a Associação dos Moradores do Porto de Trás, ainda em fins da década de 1990.

No nível macro o processo de reconhecimento tem se dado num movimento difuso, porém crescente. Embora o poder público local, vinculado às velhas oligarquias da economia cacaueira tenha historicamente ignorado as necessidades e direitos dos habitantes desta área, a articulação dos moradores do Porto em torno de seu patrimônio, através de contatos com estrangeiros e turistas que visitam a localidade de Itacaré e são atraídos pelas práticas culturais do bairro em busca dos signos de "autenticidade da cultura local", tem despertado o interesse de algumas ONGs internacionais, o que vem possibilitando alguns benefícios para os moradores do Porto.

A título de exemplo, a CARE Brasil se encarregou da construção dos banheiros nas moradias do bairro, que até muito recentemente só contava com um único banheiro público. No ano de 2006, um livro sobre "Biatatá", uma lenda do Porto foi confeccionado pelas crianças locais e publicado pela editora espanhola Libre Obert, de Barcelona. Há cerca de três anos, uma empresa turística internacional financiou a construção de um centro cultural no interior do bairro, solidificando um espaço anteriormente criado pelos jovens da "Tribo do Porto", um grupo formado por capoeiristas da área.

Estes jovens, atualmente lideram a
Associação de Moradores que está pleiteando junto a Fundação Palmares o reconhecimento do Porto de Trás como quilombo urbano, com o intuito de garantirem a manutenção do território para as famílias tradicionais locais, participarem das políticas de reparação propostas pelo Estado e gerarem capacitação profissional para a população jovem do Porto. Mediante o reconhecimento internacional das riquezas patrimoniais do Porto, a prefeitura e as empresas turísticas locais, ainda que de modo superficial, vem buscando uma aproximação com os moradores, seja citando-os como patrimônio da cultura local ou negociando sua inclusão nos calendários festivos.

O contexto etnográfico atual nos reporta à De Vos (apud Vermeulen, H. e Govers, 1994), segundo o autor, a proposição de organização social pressuposta por Frederic Barth, alega que a etnicidade, pensada enquanto organização social requer interação regulada e como elemento da cultura implica na consciência da diferença, consciência esta que pode se dar em níveis tanto baixos quanto altos. No primeiro caso, as pessoas aceitam as diferenças como adquiridas, não há um movimento étnico propriamente dito porque as reflexões não ultrapassam as fronteiras do grupo. No segundo caso, a interação aumenta, o grupo toma consciência de sua singularidade cultural e começa a exigir seus direitos de reparação. A evidência dos fatos observados nos conduz a constatação de que os moradores do Porto de Trás vêm cumprindo a trajetória de constituição de uma etnicidade própria.

\section{Conclusão}

Ainda que consideremos o fenômeno turístico como um "fato social total" que provoca mudanças avassaladoras em quase todas as sociedades onde aporta, é preciso observar que nem todas as mudanças implicam num processo de descaracterização das culturas locais. Tal qual um rizoma, este fenômeno imprevisível demonstra que o movimento dialético é possível. No caso do Porto de Trás, o turismo, 
decorrente da construção da estrada, provocou a reconfiguração do espaço urbano; acirrou a resistência étnica mediante as novas co-presenças, ao mesmo tempo em que possibilitou novos processos de interação social. São estas interações que permitem a atualização e identificação dos legados culturais locais que serão patrimonializados, tanto pelos de dentro quanto pelos de fora.

Que não se pense que o reconhecimento e a visibilidade tornaram os moradores do Porto menos atentos e desconfiados. Os novos ventos de mudança não apagaram as lembranças da segregação étnica sofrida por mais de um século. Mas é fato que parecem mais convictos ou conscientes do diferencial que a etnicidade, aqui compreendida como consciência política da diferença, lhes proporcionou, uma etnicidade construída sob os alicerces do patrimônio cultural acumulado pelo capital simbólico desta coletividade. $\mathrm{Na}$ atualidade, ser do Porto de Trás significa ter orgulho da própria origem e por ironia do destino e do capital, ser detentor da "cultura autentica do lugar”, tão cobiçada pelo turismo.

\section{Bibliografia}

Barretto, Margarita

2003 "O imprescindível aporte das Ciências Sociais para o planejamento e a compreensão do Turismo". Horizontes Antropológicos. Porto Alegre: UFRGS/ IFCH/PPGAS, Ano 9, n 29 p: 15-30

Barth, Frederik

1994 "Temáticas permanentes e emergentes na análise da etnicidade". In Vermeulen, H. e Govers, C. (org) Antropologias da Etnicidade. Para além de Ethnics Groups and Boundaries: 18- 44 Lisboa: Fim de século.

Barth, Frederik

2000 "Os grupos étnicos e suas fronteiras" In:Lask,T.(org). O guru, o iniciador e outras variações :. 25-27. Rio de Janeiro: Contra Capa.

Couto, Patrícia .A.B.

2006 "Identity and Interaction: Gazes and Reflections of Tourism". In Burns, P.M. e Novelli M. (org) Tourism and
Social Identities: global Frame works and Local Realities:715-183. Oxford/ Amsterdam: Elsevier

Couto, Patrícia .A.B.

2007 O direito ao lugar: situações processuais de conflito na reconfiguração social e territorial do município de Itacaré, BA. Tese defendida no Programa de Pós-Graduação em Antropologia da Universidade Federal Fluminense (PPGA/UFF).

Couto, Patrícia A.B.

2007a "Cupidité et conflit : une reflexion sur l'impact du tourisme dans la production de nouvelles identités sur le territoire de la municipalité d'Itacaré dans l'Etat de Bahia". In Teisserenc, P. , Milanez N. e Magalhães, S. B. (org) Le Brésil à l' epreuve de la modernité : 123-134. Paris : L'Harmattan,

Couto, Patrícia A.B.

2007b "Da viagem ao fenômeno turístico: uma breve digressão sobre sua história e inserção no campo das Ciências Sociais". Candelária. Revista do Instituto de Humanidades. Jul-Dez. Ano IV: 127-142. Rio de Janeiro: UCAM,

Elias, Norbert. e Scotson John L.

2000 Os Establecidos e os Outsiders. Rio de Janeiro: Jorge Zahar.

Falcon, Gustavo

1995 Os coronéis do cacau. Salvador: Iemanjá.

Gonçalves, José Reginaldo

2003 "O patrimônio como categoria de pensamento, ensaios contemporâneos". In Abreu, R. e Chagas, M. (org) Memória e Patrimônio, ensaios contemporâneos : 21-29. Rio de Janeiro: DP\&A

Gonçalves, José Reginaldo

2004 Patrimônio memória e etnicidade: reinvenções da cultura açoriana. VIII Congresso Luso Afro-Brasileiro de Ciências Sociais. Coimbra, Portugal.

Le Goff, Jacques

1998 Patrimonies et passions identitaires. Paris: Fayard.

Mauss, Marcel

1974 "Ensaio sobre a dádiva. Forma e razão da troca nas sociedades arcaicas". In Sociologia e Antropologia, Vol 1. São Paulo: EDUSP 
Park, Robert Ezra

1976 "A cidade: sugestões para a investigação do comportamento humano no meio urbano". In Velho, Otávio (org). O Fenômeno Urbano:27-31. Rio de Janeiro: Zahar, .

Reis, João José

2005. "Escravos e Coiteiros no Quilombo do Oitizerio - Bahia, 1806" In:Reis J. J. e Gomes, F.S. (org) Liberdade por um fio. Histórias dos Quilombos no Brasil. São Paulo: Companhia da Letras.

Sansone, Livio

2000 Os objetos da identidade negra: consumo, mercantilização, globalização e criação de culturas negras no Brasil. Mana 6(1) Abril. Disponível em http:// www.scielo.br/scielo.php?pid $=$ s0104-93132000000100004\&script=sci_arttext

Simmel, Georg

1983 "O estrangeiro". In Moraes Filho, E. (org) Sociologia. Coordenação Florestan Fernandes. São Paulo: Ática.

Spix, Johann B. von e Martius, Karl F. P. von

1981 Viagem pelo Brasil. Belo Horizonte/ São Paulo/Itatiaia:EDUSP.

Urry, John

2005 Mobility and proximity. Disponível em http://perso.wanadoo.fr/ville-en-mouvement/interventions/John_Urry. pdf.Downloaded on 4/25/2005.

Vermeulen, Hans e Govers, Cora

s/d "Introdução". In Vermeulen, H. e Govers, C. (org) Antropologias da Etnicidade.Para além de Ethinics Groups and Boundaries: 13-15. Lisboa: Fim de Século.

\section{NOTAS}

$1 \mathrm{O}$ presente artigo foi originalmente apresentado no grupo de trabalho "Turismo, cultura e sociedade: tradição e modernidade" da $27^{\text {a }}$ Reunião Brasileira de Antropologia, realizada em agosto de 2010, em Belém do Pará, Brasil. Agradeço especialmente as contribuições de Barretto e Banducci no que se refere a ampliação reflexiva deste trabalho.

2 Resultante de pesquisa realizada para minha tese de doutorado: "O direiro ao lugar: situações processuais de conflito na reconfiguração social e territorial do município de Itacaré, BA”, defendida do Programa de Pós-Graduação em Antropologia da Universidade Federal Fluminense (PPGA/UFF: 2007).

3 No referido artigo, a autora se inspira no concei to de rizoma desenvolvido por Deleuze e Guatarri, para pensar o turismo, uma vez que tal como o rizoma, o fenômeno turístico é imprevisível, nunca se sabe para onde vai expandir ou como vai ressurgir.

4 Segundo o autor, a cultura do cacau no sul da Bahia se desenvolveu em 3 ciclos: 1746/1820 - plantio e desbravamento da região seguindo-se a estagnação sem consequências; 1820/1895 - reinício do plantio com as primeiras exportações chegando a atingir 100 mil sacos; 1895/1930 - afirmação do cacau como base econômica da região sul do estado.

5 De acordo com os relatos históricos a colonização dispersa e as densas florestas de mata atlântica muito contribuíram para a fuga de escravos e as formações quilombolas desta região.

6 De acordo com os arquivos pesquisados e relativos aos projetos governamentais, o sucesso do projeto do estado da Bahia deu subsídios para a elaboração do PRODETUR NE I, que envolveu todos os estados do Nordeste e foi inicialmente financiado pelo Banco Nacional de Desenvolvimento Econômico e Social (BNDES)

7 O Porto de Trás só tem acesso pelo Rio de Contas e pelo Marimbondo.

8 Segundo Reis (2005) por ordem do governador da Bahia João de Saldanha da Gama e Mello e Torres Guedes de Brito, o Quilombo do Oitizeiro foi totalmente dizimado no ano de 1807.

Recibido:

$30 / 09 / 2010$

Reenviado:

$29 / 11 / 2010$

Aceptado:

$18 / 12 / 2010$

Sometido a evaluación por pares anónimos 